\title{
Psychosocial Intervention with a Case of Conduct Disorder
}

\author{
Ms. Arkita Pal ${ }^{1}$, Mrs. Soma Saha ${ }^{2}$, Ms. Tumpa Sen ${ }^{3}$ \\ ${ }^{1}$ Student of M.Phil in Psychiatric Social Work, Part II, Department of Psychiatric Social Work, \\ Institute of Psychiatry, IPGME \& R, Kolkata \\ ${ }^{2}$ Associate Professor in Psychiatric Social Work, Department of Psychiatric Social Work, \\ Institute of Psychiatry, IPGME \& R, Kolkata, Corresponding Author \\ ${ }^{3}$ Student of M.Phil in Psychiatric Social Work, Part I, Department of Psychiatric Social Work, \\ Institute of Psychiatry, IPGME \& R, Kolkata
}

\begin{abstract}
In this particular case of conduct disorder, it has been evident that a persistent negative attitude and social elimination of mental illness has prevailed throughout history but general people still poorly understand it. Children's conduct behaviors have been an extensive societal worry and reflected to be indications of juvenile delinquency and adult criminality. Children with conduct problems exhibit variety of troublesome and rule violating behaviors extending from annoying but relatively minor behaviors such as complaining, temper tantrums to more severe forms of rebellious behavior such as destruction, theft, and physical attack. Given this diversity, this is useful to make clinical concern to deal with behavioral divergences. In this present case, it has been inevitably shown that psychosocial management could be a good choice for a better outcome.
\end{abstract}

Case introduction : Index client Mr. S.G, 13 years old male child, studying in class VIII, Hindu, hailing from lower socio-economic status belonging from nuclear family, rural area of India.

Sources of Information : The client himself, his parents and case record file were sources of information, which were reliable and adequate.

Brief Clinical History : The client was apparently maintaining well before the age of four. At the age of four, he was admitted to a nursery school where his stealing behaviour was noticed. At the beginning he used to steal small items, such as pencil, eraser and water bottle; when mother asked about it, he lied. For his behaviour in school, authorities called his parent a number of times. At the age of 8 , when the client was in class IV, he was punished by his class teacher for these habits. Gradually his stealing habits kept increasing.

At the age of 10, he started stealing money from family members and from others. As usual, he denied having stolen the money. A few days later, he started stealing various types ofother things such as flower-plants, flower-tubs, pigeon and rabbits from his close friends' garden and also neighbour's home. Sometimes he stole pigeon in the evening time. Between the ages of 12 and 13, these habits got extremely increased. Sometimes, he silently slipped away from home atmidnight. On being asked by neighbours where he was going, he replied that he was going for a morning walk. Anyway, he was stopped and brought back to his home. His parents were very much surprised. He was scolded by his parents, but the very next day again at $6 o^{\prime}$ clock in the evening he left home to go to the same place to steal pigeons. To avoid scolding he hid the stolen pigeon behind a bush. At the age of 10, along with stealing, he also developed another habit; that is, teasing animals, mainly cats and dogs, sometimes by pulling their legs, catching their tails and swinging them; and sometimes throwing stones at them. Along with this another streak of behaviour was noticeable that included collecting papers, plastics, sticks, which ever came within his reach, and he would set them on fire. Noticing this behaviour, his 
parents kept match-boxes and gas-lighters hidden and out of his reach. He did not socialize with other children or attend school and gradually became drop out. He used to be irritable at home and got easily angry.

Complaints were raised regarding his inattentiveness in class, not completing his class work adequately \& making various silly mistakes which were not present previously. As a result, he failed and had to stay back in the same class for two years but last of all, he was promoted to next class with grace marks. Gradually, it was seen that he became very demanding with his parents (money, plastics, pigeon, etc.). He did not listen to his parents and would do what he was told not to. He would show his anger and used to hurt his mother and sister by pulling their hair and hitting. In the month of February, 2017, his destructive and aggressive behaviour increased. At that situation, his family members decided to take him to the nearer physician, but since the condition was deteriorating, he was brought to Institute Of Psychiatry (IOP, Kolkata) and subsequently the case was referred to Department of Psychiatric Social Work for psychosocial assessment and intervention.

\section{PSYCHOSOCIAL FINDINGS}

In this case, it was clearly a diagnosis of conduct disorder. He was an adolescent of less than 18 years age who presented with important symptoms which included aggression to harmless things, animals and people including his parents, deceitfulness to his parents and violation of rules either at home or school and most importantly stealing things for more than 8 years. These behaviors had affected his school attendance, academic performance as well as family interactions. The conduct problems in him were categorized as severe in which his behaviors were mainly affecting others.

The first step into the management was to understand the reasons behind his socially unacceptable behaviors. This involves good counseling skills. Through self-exploration, it was discovered that there was parenting problem; indirect communication pattern and early childhood physical punishment had actually accumulated anger in him. Poor adaptive pattern was found in the family. Family members were not able to segregate between the usual behaviours and sickness behaviours. In this family, inadequate reinforcement, cohesiveness, close and rigid boundary and laissez - faire leadership were present. They were also incapable to face the difficulties. Mother was over involved and overprotective which lead to poor capability in client to adjust in situations and developed maladaptive patterns.

A good parenting especially during the first five years of life is important for the child's secure attachment. In contrast, early use of extensive punishment and inappropriate reinforcement in children is associated with aggressive and angry adolescents. He presented his anger by being rebellious and displaying the conduct problems. The recommended management of conduct disorder includes family therapy, behavior modification and pharmacotherapy. Ideally, the management would involve a multidisciplinary team. However in our Indian context to have all of them involved are not always possible. The following management describes what has been done for this client by a psychiatric social worker.

\section{PSYCHOSOCIAL MANAGEMENT}

Parental skills : An initial meeting was programmed with client's parents. After a history of the existing problems from the parent's viewpoint was taken, his parents were asked to identify his problem behaviors, deficits, assets, and potential reinforcers. During the development of therapy, a number of vital issues were addressed like the parents had conflicts with each other and there was an apparent dissonance between the maternal and the paternal parenting styles. Client's father had a persistent belief that his wife had been maintaining an illicit relationship with her brother in - law (client's paternal uncle). Father usually returned to his house after 1-1.5 months from his service place. As his father returned 


\section{Psychosocial Intervention with a Case of Conduct Disorder}

home after a long gap and he was an alcoholic, his mother suspected him of infidelity. After thorough assessment, the therapist presented many examples of parental traps to the parents, relying on basic principles of reinforcement and using examples often encountered from real life. The sessions were also used to educate the parents, teach new skills, immediate reinforcement after positive change, correct current and new problems and evaluate the effectiveness of treatment variables.

Psychoeducation: In this present case it was reported that unawareness of the illness led to developing other causes of distress among the family members and the client himself. Considering the social stigma and burden, the client was given an understanding of the illness viz. possible causes, course and prognosis and treatment outcomes by keeping supportive measures like guidance, reassurance, and clarification. The client was given awareness by preparing a chart where he was asked to note his desire to escape from Inpatient Department, taking others' property without permission and desire to set fire by maintaining the record log. He maintained the record log, which showed a gradual decrement in the frequency of aforesaid desires. Then the therapist showed him the difference between the frequency and the occurrences of his desires of doing offensive acts. Subsequently, he gained his knowledge about his illness.

Problem Solving Skill Training for behavioral change : Before imparting training the client's motivation was assessed. After enhancing his motivation and interest, he was given an introduction to problem-solving skill training. The problems were assessed by discussing with the client and his parents on the basis of priority. Therapist was helping client to change his socially unacceptable behavior and hence resume his function as student and child. Behavioral change is rarely a discrete event and often takes place gradually. Getting him to attend school class was the main focus. In order to ensure he had enough rest in the morning, parents and client had agreed to allow his outing time to a fixed period where he can see things but cannot collect any. Initially it was difficult but phone calls from the mother and the pro-activeness from the father to look for him helped a lot to monitor his undesired behavior. This also had helped him to feel welcome and less disparage in neighborhood. With time, steadily once his anger had been controlled together with the improvement in his family interaction, his conduct problems had slowly reduced.

\section{PROGRESS}

On the last visit of the tenth counseling session, he had shown a remarkable improvement. He had started making new friends. His outing time had reduced and harming any pigeon or hen or other animals had also come down. He attended his school class regularly and had started preparing himself for study. Both parents were happy with his progress and they were reminded on the needs for them to be consistent in their parenting.

\section{CONCLUSIONS AND RECOMMENDATIONS}

The success of conduct problem management depends on the adolescents' motivation in the department attendance, practicing the skills that they have learned in their daily practice as well as the setup of the service in the hospital. In this case, there were times when the adolescent lost focus and motivation. However, good commitment from both parents had actually resulted in a promising outcome. The therapy is still going on in terms of family dynamics. This adolescent definitely requires the continuity of care and reinforcement of anger management to prevent relapse. In short as psychiatric social worker, our role is to be able to detect conduct problems in the community, assess its severity, to treat the uncomplicated cases in the beginning and refer difficult cases for specialized treatment. The decision to treat these children with conduct problems especially the severe one is very much related to our clinical exposure and experience. In doubtful cases, the referral to clinical psychologist and child psychiatrist is very much 
Psychosocial Intervention with a Case of Conduct Disorder

desired and cannot be denied. It is unfortunate if these adolescents are left unassisted as evidence has shown that many of them will have poor socioeconomic status and personality disorder in adult life later.

\section{REFERENCES}

1. Adams JF. Impact of parent training on family functioning. Child and Family Behavior Therapy. 2001; $23: 29-42$.

2. Alexander JF, Robbins MS. Functional family therapy: a phase-based and multicomponent approach to change. In : Murrihy RC, Ollendick $\mathrm{TH}$, Kidman AD, eds. Clinical Handbook of Assessing and Treating Conduct Problems in Youth. 1st edn. New York, NY : Springer Verlag; 2010. p. 245-71.

3. Ashkar PJ, Kenny DT. Views from the inside : young offenders' subjective experiences of incarceration. International Journal of Offender Therapy and Comparative Criminology. 2008; $52: 584-97$.

4. Baker-Henningham H, Scott S, Jones K, Walker S. Reducing child conduct problems and promoting social skills in a middle-income country: cluster randomised controlled trial. British Journal of Psychiatry. 2012; 201 : 1-8.

5. Carnes-Holt K. Child-parent relationship therapy (CPRT) with adoptive families : effects on child behavior, parent-child relationship stress, and parental empathy [dissertation]. Denton, TX : University of North Texas; 2010.

6. Cefai C, Cooper P. Students without voices: the unheard accounts of secondary school students with social, emotional and behaviour difficulties. European Journal of Special Needs Education. 2010; 25 : 183-98.

7. Dadds MR, McHugh TA. Social support and treatment outcome in behavioral family therapy for child conduct problems. Journal of
Consulting and Clinical Psychology. 1992; 60 : 252-59.

8. Elias LC, Marturano EM, Motta AM, Giurlani AG. Treating boys with low school achievement and behavior problems: comparison of two kinds of intervention. Psychological Reports. 2003; 92 : 105-16.

9. Kannappan R, Bai RL. Efficacy of yoga : cognitive and human relationship training for correcting maladjustment behaviour in deviant school boys. Journal of the Indian Academy of Applied Psychology. 2008; 34 : 60-65.

10. Lochman JE. Parent and family skills training in targeted prevention programs for at-risk youth. The Journal of Primary Prevention. 2000; 21 : 253-65.

11. Markie-Dadds C, Sanders MR. a controlled evaluation of an enhanced self-directed behavioural family intervention for parents of children with conduct problems in rural and remote areas. Behaviour Change. 2006a; 23 : $55-72$.

12. Rao SA. The short-term impact of the family check-up: A brief motivational intervention for at-risk families [dissertation]. Eugene, OR : University of Oregon; 1998.

13. Soderlund J, Epstein MH, Quinn KP, Cumblad C, Petersen S. Parental perspectives on comprehensive services for children and youth with emotional and behavioral disorders. Behavioral Disorders. 1995; 20 : 157-70.

14. Walker HM, Kavanagh K, Stiller B, Golly A, Severson HH, Feil EG. First step to success: an early intervention approach for preventing school antisocial behavior. Journal of Emotional and Behavioral Disorders. 1998; 6 : 66-80.

15. Weinblatt $U$, Omer $H$. Nonviolent resistance: A treatment for parents of children with acute behavior problems. Journal of Marital and Family Therapy. 2008; 34 : 75- 92. 